\title{
Spirometry use: detection of chronic obstructive pulmonary disease in the primary care setting
}

This article was published in the following Dove Press journal:

Clinical Interventions in Aging

25 January $201 \mathrm{I}$

Number of times this article has been viewed

\author{
Thomas A Barnes' \\ Len Fromer ${ }^{2}$ \\ 'Department of Cardiopulmonary \\ Sciences, Northeastern University, \\ Boston, MA, USA; ${ }^{2}$ David Geffen \\ School of Medicine at UCLA, \\ Los Angeles, CA, USA
}

Correspondence: Thomas A Barnes Northeastern University, 316 Robinson Hall, Boston, MA 02II5-5000, USA

Tel +l 6173733666

Cell +l 6178513529

Email t.barnes@neu.edu
Objective: To describe a practical method for family practitioners to stage chronic obstructive pulmonary disease (COPD) by the use of office spirometry.

Methods: This is a review of the lessons learned from evaluations of the use of office spirometry in the primary care setting to identify best practices using the most recent published evaluations of office spirometry and the analysis of preliminary data from a recent spirometry mass screening project. A mass screening study by the American Association for Respiratory Care and the COPD Foundation was used to identify the most effective way for general practitioners to implement office spirometry in order to stage COPD.

Results: A simple three-step method is described to identify people with a high pre-test probability in an attempt to detect moderate to severe COPD: COPD questionnaire, measurement of peak expiratory flow, and office spirometry. Clinical practice guidelines exist for office spirometry basics for safety, use of electronic peak flow devices, and portable spirometers.

Conclusion: Spirometry can be undertaken in primary care offices with acceptable levels of technical expertise. Using office spirometry, primary care physicians can diagnose the presence and severity of COPD. Spirometry can guide therapies for COPD and predict outcomes when used in general practice.

Keywords: chronic obstructive pulmonary disease, spirometry, family practice, primary care physician

\section{Introduction}

Spirometry is the most reproducible, standardized, and objective way of measuring airflow obstruction for the diagnosis and management of chronic obstructive pulmonary disease (COPD). ${ }^{1}$ The spirogram, first described by John Hutchinson in 1846, is the oldest clinical test still in use today to measure patients' maximum exhalations from total lung capacity. ${ }^{2}$ In obstructive pulmonary disease, the changes seen in spirometry are a reduction in forced expiratory volume in the first second $\left(\mathrm{FEV}_{1}\right)$ - commonly referred to as "airflow" in primary practice - with respect to forced vital capacity (FVC). Using these measurements, the primary care physician can diagnose the presence and severity of airway obstruction ${ }^{3,4}$ and assess the risk of COPD, lung cancer, coronary artery disease, and stroke. ${ }^{5}$ Spirometry can be incorporated into family practice with acceptable levels of technical adequacy and accurate interpretations, ${ }^{6}$ the results of which have been shown to influence general practitioner management of patients with previously diagnosed asthma and COPD. ${ }^{3}$ A recent evidence-based review project ${ }^{7}$ concluded that spirometry by primary care physicians should be reserved for high-risk subjects, eg, smokers aged $>40$ years with symptoms, who would benefit from in-depth evaluation 
and management. ${ }^{4,89}$ All smokers should be encouraged to stop smoking, regardless of whether or not they have COPD. Although it has been argued that office spirometry should not be used to encourage smokers to stop, because a normal spirogram in an active smoker may encourage continuation of the behavior and give a patient a false sense of being disease free, ${ }^{10-12}$ it has been demonstrated that abnormal spirometry and informing a patient of their "lung age" are effective strategies in encouraging smoking cessation. ${ }^{7,13}$

The exact definition of COPD can be complex but should be considered in a patient who has dyspnea, chronic cough, or sputum production and/or a history of exposure to risk factors (eg, smoking/second-hand smoke, or biomass fuels) with airflow obstruction that is partially reversible with acute use of bronchodilators. ${ }^{1}$ Typically, patients with asthma respond more fully to bronchodilators than those with COPD, but there is no clear-cut presentation; for example, patients with well established COPD have been shown to have better responsiveness to acute use of bronchodilators than previously expected, ${ }^{14}$ and asthmatics may have very little airway dilation, especially if they have used their bronchodilator therapy before arriving for spirometry. Some asthma patients will not exhibit substantial airway responsiveness to bronchodilators until their therapy has the asthma under better control. ${ }^{15}$ Basing clinical decisions and plans on airway response to bronchodilators is therefore often controversial.

The severity of COPD should be assessed once the diagnosis has been made using the 2009 updated guidelines from the Global Initiative for Chronic Lung Disease (GOLD) to determine the degree of spirometric abnormality and by the presence of complications, such as respiratory failure and/or right-sided heart failure. ${ }^{1,16,17}$ The GOLD guidelines propose four stages of COPD based on spirometry: $\mathrm{FEV}_{1} /$ FVC ratio $<0.70$ and $\mathrm{FEV}_{1}>80 \%$ predicted (Stage 1 Mild), $\mathrm{FEV}_{1}$ of $50 \%-80 \%$ predicted (Stage 2 Moderate), $\mathrm{FEV}_{1}$ of $30 \%-50 \%$ predicted (Stage 3 Severe), and $\mathrm{FEV}_{1}<30 \%$ predicted or $\mathrm{FEV}_{1}<50 \%$ predicted plus chronic respiratory failure (Stage 4 Very Severe). Patients with symptoms of GOLD Stage 1 COPD can have significant abnormalities of ventilatory mechanics with greater exertional symptoms and exercise limitation than age-matched healthy subjects. ${ }^{18}$

\section{Is screening spirometry a waste of resources?}

Spirometry should be used to stage COPD and to guide therapy. Diagnosing airflow obstruction is important because there are effective therapeutic interventions in asthma and
COPD that improve outcomes. ${ }^{1,16}$ Staging COPD using the GOLD guidelines for $\mathrm{FEV}_{1} / \mathrm{FVC}$ ratio and $\mathrm{FEV}_{1}$ in general practice with office spirometry provides a logical framework to guide therapy. Examples of interventions include smoking cessation, ${ }^{19}$ drugs, ${ }^{20,21}$ oxygen, ${ }^{22}$ rehabilitation, ${ }^{23}$ and surgical options. ${ }^{24}$ Treatment goals should include improving quality of life and exercise tolerance and decreasing the number of exacerbations. If exacerbations can be reduced, then health care costs will be reduced by fewer hospitalizations and visits to the emergency department. It is important to confirm that respiratory symptoms suggest COPD and are the result of airflow obstruction. A decision will need to be made regarding whether a bronchodilator via an inhaler should be administered to improve airflow.

The prevalence of COPD in a primary care setting in patients with a smoking history and self-reported bronchitis has been studied. ${ }^{25,26}$ A recent multicenter, cross-sectional study by Yawn et al determined the percentage of patients with airway obstruction (post-bronchodilator $\mathrm{FEV}_{1} / \mathrm{FVC}$ ratio $\leq 0.70$ ) compared with those without airway obstruction (post-bronchodilator $\mathrm{FEV}_{1} / \mathrm{FVC}$ ratio $>0.70$ ) and confirmed $26 \%$ patients with airflow obstruction consistent with COPD. This latter group had a mean age of 52.9 years, an $\mathrm{FEV}_{1}$ of $81.4 \%$ predicted, a smoking history of 39.8 pack-years, and reported chronic bronchitis symptoms. ${ }^{26}$ Airflow obstruction has been observed to increase with age and smoking history, and Yawn et al noted that slight or moderate dyspnea was reported by $68 \%$ of the patients with a post-bronchodilator $\mathrm{FEV}_{1} / \mathrm{FVC}$ ratio $\leq 0.70 .{ }^{26}$ The majority of the patients with newly diagnosed COPD had not discussed their coughing with their doctor and continued to smoke. ${ }^{26}$ Several studies around the globe have found that many patients with COPD remain undiagnosed in the primary care setting. . $^{825,26}$ Use of spirometry in patients with a smoking history and chronic bronchitis symptoms can aid in the diagnosis of COPD, allowing early treatment; $8,25,26$ however, screening patients at risk of COPD remains controversial, ${ }^{1}$ and the US Preventive Services Task Force (USPSTF) recommends against screening adults for COPD using spirometry following a systematic review of evidence of the benefits and harms and an assessment of the net benefit. ${ }^{27}$ Each patient needs to be evaluated individually, according to their smoking history, lifestyle, and comorbidities, prior to a decision to perform spirometry.

\section{Lessons learned from mass screening experience}

The lessons learned from mass screening of people outside of primary care offices have led to the following 
recommendations by the American Association for Respiratory Care (AARC) and the COPD Foundation: ${ }^{28}$

1. Use a COPD questionnaire to identify those at risk.

2. Use an electronic device to detect those likely to have a low peak flow.

3. Only perform spirometry on those at higher risk of COPD (smoking, biomass fuel exposure).

4. Take the time to perform good spirometry.

The AARC, the COPD Foundation, and Columbia University have completed a pilot study, ${ }^{29}$ which screened 4901 people for COPD using a shortened version of the Martinez et al population screening questionnaire, ${ }^{30}$ peak expiratory flow measurement (PEF), and spirometry. The study used a three-step method (Figure 1) ${ }^{29}$ to identify people with a high pre-test probability in an attempt to detect moderate to severe COPD. ${ }^{28,29}$

\section{Spirometry basics}

Spirometry is the gold standard for the diagnosis and assessment of COPD, as it is the most reproducible, standardized, and objective way of measuring airflow obstruction. ${ }^{1}$ It also detects airway obstruction in people with poorly controlled asthma. If PEF is $<70 \%$ predicted, simple spirometry should be performed on a portable spirometer.

Spirometry can be undertaken in primary care offices with acceptable levels of technical adequacy and accurate interpretations, and can alter clinical decisions in the management of asthma and COPD. ${ }^{6,31}$ In April 2010, the Office Spirometry Certificate (OSC) was presented to the AARC state representatives meetings; it was presented again at the American Thoracic Association meeting (ATS) in May 2010. The OSC is a national initiative whose aim is to "teach practitioners to obtain good quality spirometry $>90 \%$ of the time, standardize testing performed in the office setting, assure test accuracy and validity and to ensure staff competency" (http://www.aarc.org/osc/). The process consists of an Internet-based online exam and additional direct competency-based testing, and is intended to provide a way for people outside the traditional pulmonary function laboratory setting to demonstrate understanding and receive quality feedback on performance. Having two trained and certified spirometer experts as part of a practice team is the ideal situation in which to provide the most readily available and reliable spirometry.

The National Lung Health Education Program (NLHEP) has recommended that all smokers aged 45 years and older have a screening lung function measured by simple spirometry; ${ }^{32}$ however, PEF is quicker to measure than spirometry, ${ }^{33}$ although this would require two devices and would not be supported by all health authorities. Older patients often have multiple chronic health problems that can magnify the impact of COPD on a patient's health status

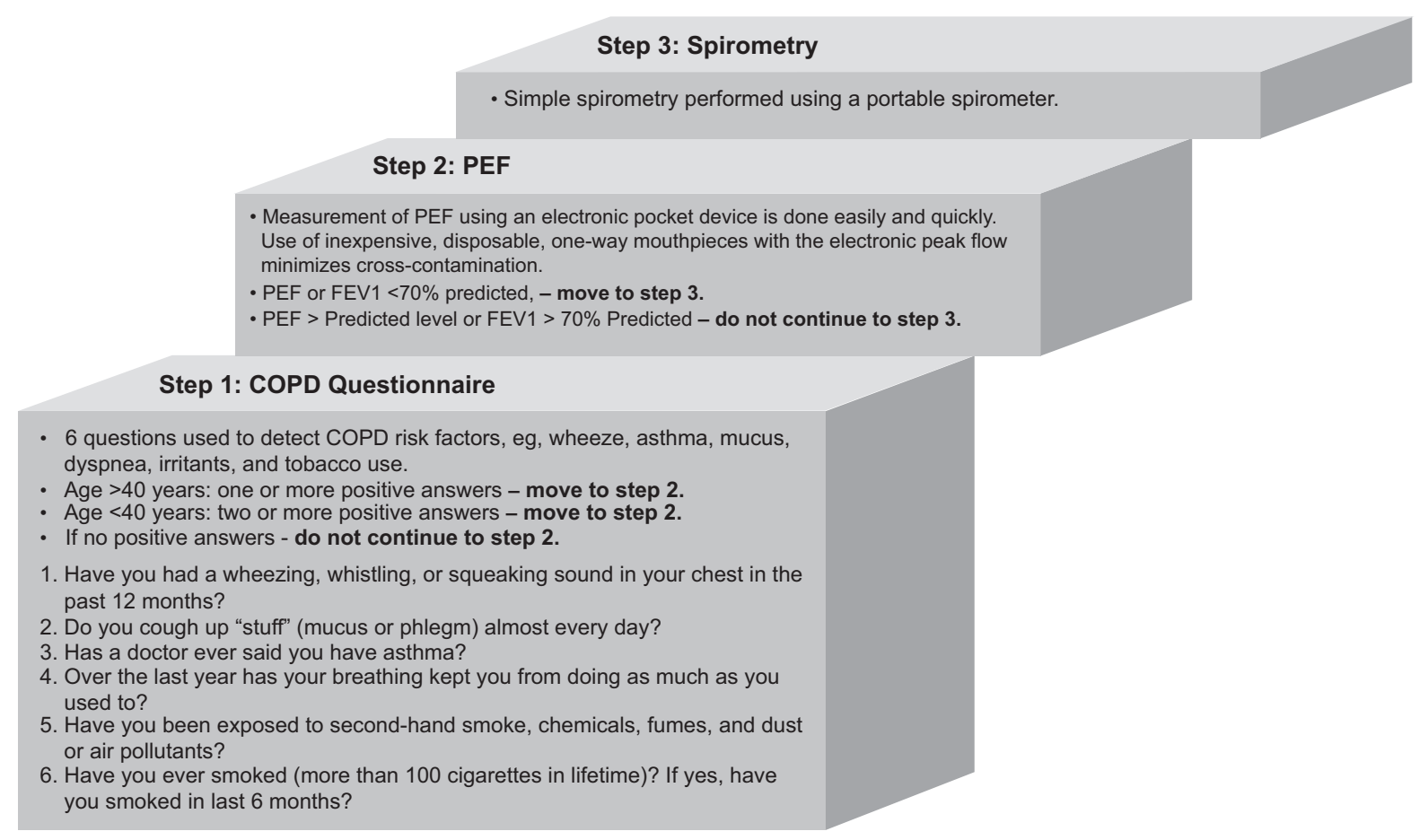

Figure I Three-step method to identify people with a high pre-test probability for moderate to severe COPD..$^{29}$

Abbreviations: COPD, chronic obstructive pulmonary disease; FEV , forced expiratory volume in the first second; PEF, peak expiratory flow measurement. 
Table I Precautions to be taken during spirometry

I. Consider spirometry contraindications, eg, hemoptysis of unknown origin (forced expiratory maneuver may aggravate the underlying condition); pneumothorax; unstable cardiovascular status (forced expiratory maneuver may worsen angina or cause changes in blood pressure), or recent myocardial infarction, or pulmonary embolus; thoracic, abdominal, or cerebral aneurysms (danger of rupture due to increased thoracic pressure); recent eye surgery; presence of an acute disease process that might interfere with test performance (nausea, vomiting); recent surgery of thorax or abdomen.

2. Ask the patient to sit in a comfortable chair (prevent falls and fatigue).

3. Wash your hands, keep hands away from your nose and mouth, and stay home if you have a cold or the flu.

4. Wipe the spirometer with an alcohol pad.

and can complicate the management of COPD. Confirming the diagnosis of COPD is an important first step. The prevalence of airway obstruction in the US increases in smokers aged $>40$ years and reaches a peak of $31 \%$ in all men aged 65-75 years who are currently smoking. ${ }^{34}$ In 2004, the NLHEP implemented a spirometer review process to encourage the development of simple office-based spirometers for use in the primary care setting. ${ }^{35}$ The goal of this process is to clarify the elements required to make a device appropriate for use in the primary care physician's office and to provide a checklist of these elements for use by companies and reviewers to validate the device. As of January 2010, the NLHEP has approved four outpatient spirometers, which are reliable, accurate, and affordable; these are listed on the NLHEP website with links to the manufacturers of the devices. ${ }^{35}$ They comprise the NDD EasyOne Frontline 2000-2, the EasyOne Diagnostic 2001-2 (www.nddmed.com), the CP200 models (CP2AS-1E1 and CP2S-1E1 [Welch Allyn; www.welchallyn.com]), and the Astra300 (SDI Diagnostics; www.sdidiagnostics.com).

\section{Safety}

Members of the practice office staff trained to carry out spirometry should take the precautions described in Table 1.

\section{Pocket spirometry for PEF}

An inexpensive (US\$50) electronic device with disposable mouthpieces should be used. ${ }^{36}$ The first step is for

Table 2 A procedure for spirometry

\footnotetext{
I. Wash hands (staff person and patient).

2. Reassure the patient.

3. Review pre-test questionnaire.

4. Carefully enter data into the spirometer.

5. "Demonstrate" the maneuver.

6. Coach and observe body language.

7. Obtain three good maneuvers.
}

Table 3 Common problems during office spirometry and the appropriate solutions

\begin{tabular}{ll}
\hline Problem & Solution \\
\hline Hesitant starts & For the next maneuver, watch the patient \\
& inhale deeply, then shout "blast" before they \\
& start to exhale. \\
Poor blast effort & Need more aggressive coaching (not due \\
& to lung disease). \\
& Enthusiastically demonstrate the FVC \\
& maneuver again. Yell "blast" after the deep \\
& inhalation and before they start to exhale. \\
& Need more aggressive coaching (not due \\
Short maneuvers & The lung disease). \\
out longer. & Dramatically demonstrate a deep breath \\
and encourage maximal inhalation before \\
the breath. \\
Caused by nasal inhalations during \\
exhalation. \\
Reject these maneuvers and then use nose \\
clips.
\end{tabular}

Abbreviation: FVC, forced vital capacity.

the practice office staff to write down the predicted PEF using age and height from gender- and race-specific tables. The maneuver should be demonstrated with the mouthpiece (after a deep breath, coaching the patient to "blast" out the air). The practice office staff should attach a clean mouthpiece without touching it, and encourage a deep breath from the patient and then a 1-second blast. The maneuver should be repeated in cases of low or poor effort by the patient.

\section{Spirometry to measure only $\mathrm{FEV}$, and $\mathrm{FEV}, / \mathrm{FVC}$ ratio}

In the US, Medicare payments for office spirometry averaged about US\$40 during 2009 and allowed the cost to be covered after 25 tests. The office staff administering spirometry should dramatically demonstrate the three steps for the FVC maneuver: 1) "deep" inhalation, 2) "blast" out, and 3) "keep blowing" for 6 seconds. A procedure for spirometry is described in Table 2.

Table 4 Overall spirometry test session quality goals

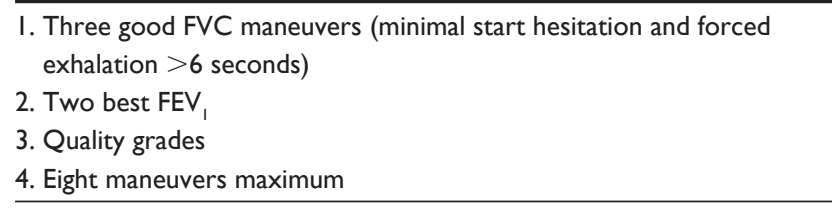
Abbreviations: $\mathrm{FEV}$, forced expiratory volume in the first second; FVC, forced vital capacity. 
Common mistakes or problems encountered during office spirometry and the appropriate solutions can be found in Table 3.

Overall test session quality goals for spirometry technique should include those described in Table $4 .{ }^{37}$ Modern portable spirometers are programmed to apply the ATS recommendations for good maneuvers, and this, together with certification (OSC) of well trained spirometry experts, will help to improve the quality of office spirometry.

Quality spirometry is best achieved by gaining rapport with the patient and by dramatically demonstrating the maneuver, closely observing the patient's body language during the maneuver, repeating the demonstration as needed, and repeating the maneuver after a rest. Submaximal maneuvers will frequently cause falsely high and falsely low results. There can be a wide range of quality among staff who administer the spirometry tests; however, with a quality assurance program, spirometry can be performed and interpreted for asthma and COPD patients, and the spirometry results used to modify care. ${ }^{35}$ Even the elderly can perform good spirometry. ${ }^{37}$

\section{Conclusion}

Staging of COPD is driven by percent predicted $\mathrm{FEV}_{1}$ and $\mathrm{FEV}_{1} / \mathrm{FVC}$ ratio (providing the spirometry is carried out correctly); however, this takes only one piece of information into account. The authors advise that the reality of concordance of symptoms (according to the validated St Georges Respiratory Questionnaire ${ }^{38}$ and the newly developed short Clinical COPD Questionnaire ${ }^{39}$ and the impact of COPD on a patient's daily living according to their individual needs/occupation should be taken into account. Although it has been suggested that PEF can be used rather than spirometry ${ }^{33}$ this is not the case in primary care, as the gold standard in diagnosing and tracking the path of COPD is spirometry, $\mathrm{FEV}_{1}$, and the $\mathrm{FEV}_{1} / \mathrm{FVC}$ ratio. Using spirometry, primary care physicians can diagnose the presence and severity of COPD. In summary, spirometry can guide therapies for COPD and predict outcomes when used in a primary care setting.

\section{Acknowledgments}

This article was developed on the basis of the authors' presentations and discussions at "Overcoming Barriers to COPD Identification and Management", held in New York, NY, USA, 23-24 March 2009. This meeting, the authors' participation, and manuscript preparation were supported by Boehringer Ingelheim Pharmaceuticals Inc. and Pfizer Inc. Medical writing assistance was provided by Gill Sperrin CBiol MSB of Envision Scientific Solutions. The article reflects the concepts of the authors and is their sole responsibility. It was not reviewed by Boehringer Ingelheim Pharmaceuticals Inc. or Pfizer Inc., except to ensure medical and safety accuracy.

\section{Disclosures}

Tom Barnes has received consultation fees from Boehringer Ingelheim Pharmaceuticals Inc. and Pfizer. Len Fromer has received honoraria for speakers' bureau from Boehringer Ingelheim Pharmaceuticals Inc. and Pfizer.

\section{References}

1. Global Initiative for Chronic Obstructive Lung Disease (GOLD). Global strategy for the diagnosis, management and prevention of chronic obstructive pulmonary disease, 2009. Available from: http://www. goldcopd.org. Accessed Jan15 2010.

2. Petty TL. John Hutchinson's mysterious machine revisited. Chest. 2002; 121 Suppl 5:S219-S223.

3. Chavannes N, Schermer T, Akkermans R, et al. Impact of spirometry on GPs' diagnostic differentiation and decision-making. Respir Med. 2004;98(11):1124-1130.

4. Dales RE, Vandemheen KL, Clinch J, et al. Spirometry in the primary care setting: influence on clinical diagnosis and management of airflow obstruction. Chest. 2005;128(4):2443-2447.

5. Young RP, Hopkins R, Eaton TE. Forced expiratory volume in one second: not just a lung function test but a marker of premature death from all causes. Eur Respir J. 2007;30(4):616-622.

6. Yawn BP, Enright PL, Lemanske RF Jr, et al. Spirometry can be done in family physicians' offices and alters clinical decisions in management of asthma and COPD. Chest. 2007;132(4): 1162-1168.

7. Lin K, Watkins B, Johnson T, et al. Screening for chronic obstructive pulmonary disease using spirometry: summary of the evidence for the US Preventive Services Task Force. Ann Intern Med. 2008;148(7): 535-543.

8. Bednarek M, Maciejewski J, Wozniak M, et al. Prevalence, severity and underdiagnosis of COPD in the primary care setting. Thorax. 2008; 63(5):402-407.

9. Lusuardi M, de Benedetto F, Paggiaro P, et al. A randomized controlled trial on office spirometry in asthma and COPD in standard general practice: data from spirometry in asthma and COPD: a comparative evaluation Italian study. Chest. 2006;129(4):844-852.

10. Buffels J, Degryse J, Decramer M, et al. Spirometry and smoking cessation advice in general practice: a randomised clinical trial. Respir Med. 2006;100(11):2012-2017.

11. Enright P. Does screening for COPD by primary care physicians have the potential to cause more harm than good? Chest. 2006;129(4): 833-835.

12. Stratelis G, Molstad S, Jakobsson P, et al. The impact of repeated spirometry and smoking cessation advice on smokers with mild COPD. Scand J Prim Health Care. 2006;24(3):133-139.

13. Tashkin DP, Murray RP. Smoking cessation in chronic obstructive pulmonary disease. Respir Med. 2009;103(7):963-974.

14. Tashkin DP, Celli B, Decramer M, et al. Bronchodilator responsiveness in patients with COPD. Eur Respir J. 2008;31(4):742-750.

15. McCormack MC, Enright PL. Making the diagnosis of asthma. Respir Care. 2008;53(5):583-590; discussion 590-592.

16. Gold PM. The 2007 GOLD Guidelines: a comprehensive care framework. Respir Care. 2009;54(8):1040-1049. 
17. Macintyre NR. Spirometry for the diagnosis and management of chronic obstructive pulmonary disease. Respir Care. 2009;54(8): 1050-1057.

18. O'Donnell DE, Laveneziana P, Ora J, et al. Evaluation of acute bronchodilator reversibility in patients with symptoms of GOLD stage I COPD. Thorax. 2009;64(3):216-223.

19. Goodfellow LT, Waugh JB. Tobacco treatment and prevention: what works and why. Respir Care. 2009;54(8):1082-1090.

20. Celli BR, Thomas NE, Anderson JA, et al. Effect of pharmacotherapy on rate of decline of lung function in chronic obstructive pulmonary disease: results from the TORCH study. Am J Respir Crit Care Med. 2008;178(4):332-338.

21. Restrepo RD. A stepwise approach to management of stable COPD with inhaled pharmacotherapy: a review. Respir Care. 2009;54(8): 1058-1081.

22. Tarpy SP, Celli BR. Long-term oxygen therapy. N Engl J Med. 1995; 333(11):710-714.

23. Lacasse Y, Goldstein R, Lasserson TJ, et al. Pulmonary rehabilitation for chronic obstructive pulmonary disease. Cochrane Database Syst Rev. 2006;4:CD003793.

24. Fishman A, Martinez F, Naunheim K, et al; National Emphysema Treatment Trial Research Group. A randomized trial comparing lungvolume-reduction surgery with medical therapy for severe emphysema. N Engl J Med. 2003;348(21):2059-2073.

25. Leuppi JD, Miedinger D, Chhajed PN, et al. Quality of spirometry in primary care for case finding of airway obstruction in smokers. Respiration. 2010;79(6):469-474.

26. Yawn B, Mannino D, Littlejohn T, et al. Prevalence of COPD among symptomatic patients in a primary care setting. Curr Med Res Opin. 2009;25(11):2671-2677.

27. US Preventive Services Task Force. Screening for chronic obstructive pulmonary disease using spirometry: US Preventive Services Task Force recommendation statement. Ann Intern Med. 2008;148(7): $529-534$.
28. COPD Foundation. Mobile spirometry unit, 2010. Available from: http:// www.copdfoundation.org/Programs/MobileSpirometryUnit/tabid/104/ language/en-US/Default.aspx. Accessed Nov 242010.

29. Nelson SB, Thomashaw BM, Enright P, et al. A tiered, economical approach for COPD case-finding in the general population. Am J Respir Crit Care Med 2010;181:A5949.

30. Martinez FJ, Raczek AE, Seifer FD, et al. Development and initial validation of a self-scored COPD Population Screener Questionnaire (COPD-PS). COPD. 2008;5(2):85-95.

31. Lamprecht B, Schirnhofer L, Tiefenbacher F, et al. Six-second spirometry for detection of airway obstruction: a population-based study in Austria. Am J Respir Crit Care Med. 2007;176(5):460-464.

32. The National Lung Health Education Program (NLHEP). Strategies in preserving lung health and preventing COPD and associated diseases. Chest. 1998;113 Suppl 2:S123-S163.

33. White P. Spirometry and peak expiratory flow in the primary care management of COPD. Prim Care Respir J. 2004;13(1):5-8.

34. Mannino DM. COPD: epidemiology, prevalence, morbidity and mortality, and disease heterogeneity. Chest. 2002;121 Suppl 5:S121-S126.

35. American Association for Respiratory Care Dallas Texas. National Lung Health Education Program - Spirometer Review Process, 2007. Available from: http://www.nlhep.org/spirometer-review-process.html. Accessed 2010 Nov 24.

36. Vitalograph Ltd Buckingham England. Electronic peak flow meters, 2009. Available from: http://www.vitalograph.co.uk/products/ asma-1.php. Accessed Nov 242010.

37. Enright PL. How to make sure your spirometry tests are of good quality. Respir Care. 2003;48(8):773-776.

38. Engstrom CP, Persson LO, Larsson S, et al. Reliability and validity of a Swedish version of the St. George's Respiratory Questionnaire. Eur Respir J. 1998;11(1):61-66.

39. Stallberg B, Nokela M, Ehrs PO, et al. Validation of the Clinical COPD Questionnaire (CCQ) in primary care. Health Qual Life Outcomes. 2009; 7:26.
Clinical Interventions in Aging

\section{Publish your work in this journal}

Clinical Interventions in Aging is an international, peer-reviewed journal focusing on evidence-based reports on the value or lack thereof of treatments intended to prevent or delay the onset of maladaptive correlates of aging in human beings. This journal is indexed on PubMed Central, MedLine, the American Chemical Society's 'Chemical Abstracts Ser-

\section{Dovepress}

vice' (CAS), Scopus and the Elsevier Bibliographic databases. The manuscript management system is completely online and includes a very quick and fair peer-review system, which is all easy to use. Visit http://www.dovepress.com/testimonials.php to read real quotes from published authors. 